\title{
ТЕОРЕТИЧЕСКИЕ ОСНОВЫ ВЗАИМОСВЯЗИ НАЛОГОВЫХ БАЗ ОТДЕЛЬНЫХ НАЛОГОВ
}

\begin{abstract}
Аннотация: В статье обосновывается необходимость развития механизма администрирования налоговых баз, как важнейших элементов налогообложения. При этом важнейтим фактором построения налоговой системы должно стать обеспечение взаимосвязи и взаимообусловленности налоговых баз по всей системе функичонирующих налогов.Сделан вывод о иелесообразности формирования налоговой системы, основывающейся на принципе унификации налоговых баз взаимосвязанных налогов. Bопросы унификации налоговых баз рассматривается с учетом обеспечения эффективности налогового администрирования.

Ключевые слова: Налоги и налообложение, база, администрирование, система, политика, контроль, управление, унификация, совершенствование, механизм
\end{abstract}

условиях смены приоритетных направлений социально-экономической и налоговой политики России, как ее неотъемлемой составной части, отказа от увеличения фискального давления на экономику, сокращения количества действующих налогов и сборов при все возрастающей роли регулирующего воздействия налогов на экономических субъектов возрастают требования к повышению эффективности налогового администрирования и его совершенствованию. В последнее время все более актуальными с точки зрения практического внедрения становятся исследования, посвященные не только общетеоретическим, концептуальным вопросам налогового администрирования, которым со стороны российских ученых уделялось и продолжает уделяться большое внимание, но и более конкретных сегментов управления налоговой систе- мой, как, например, администрирование крупнейших налогоплательщиков или отдельных налогов. Вместе с тем представляется, что дальнейшее развитие налогового администрирования и повышение его качества довольно затруднительно без теоретического осмысления частных вопросов, затрагивающих методологические и методические особенности отдельных направлений управленческой деятельности в налоговой сфере. Использование в научном и практическом обороте понятия «налоговое администрирование» применительно к конкретным областям управления в налоговой сфере позволит более детально изучать, четко и ясно описывать управленческие процессы в области налоговых отношений, углубит знания общей теории налогового администрирования, равно как и повысит эффективность реализуемых на практике мероприятий в сфере налогов. 
Одним из важнейших направлений осуществляемой в наши дни налоговой реформы, отражающим качественные сдвиги в налоговой политике российского государства, выступает отказ от увеличения и даже сокращение налоговой нагрузки на экономику, что на практике выразилось в снижении налоговых ставок по ряду налогов, расширении перечня налоговых льгот и оснований для их применения. Очевидно, что в данной ситуации, принимая во внимание необходимость обеспечения более полного поступления налогов в бюджетную систему страны, особенно в условиях кризисного и посткризисного состояния экономики, на первый план выходят вопросы изучения механизма администрирования налоговых баз.

Гончаренко Л.И. справедливо отмечает, что в конце XX века сформировалась новая классификационная характеристика налоговой системы, заключающаяся в наличии взаимосвязи элементов налоговой базы отдельных налогов, реализация которой в НК РФ рассматривается как фактор создания эффективных барьеров, препятствующих применению налоговых схем $^{1}$. В связи с тем, что налоговая база и порядок ее определения устанавливаются применительно к конкретным налогам, образующим систему, элементы которой должны находиться в определенной взаимосвязи, все более актуальными вопросами в настоящее время становятся вопросы теоретического обоснования и определения взаимосвязи и взаимообусловленности налоговых баз по разным

\footnotetext{
${ }^{1}$ Гончаренко Л.И. Методология налогообложения и налогового администрирования коммерческих банков России. Афтореф. дис. ... док. экон. наук. Москва, 2009. С. 10.
}

налогам, которые должны учитываться в процессе налогового администрирования.

Взаимосвязь налоговых баз по различным группам налогов создает предпосылки для унификации механизмов их исчисления, что, несомненно, приведет к упрощению всей налоговой системы страны, снижению издержек и повышению эффективности налогового контроля - ошибки, выявленные при исчислении налоговой базы по какомулибо одному налогу, могут автоматически указывать на вероятность наличия ошибок в исчислении налоговых баз по ряду налогов. Следует учитывать, что «система налогов должна представлять такое сочетание налогов, которое давало бы возможность взаимной проверки показаний, уменьшало бы выгоду неправильных деклараций» ${ }^{2}$. Особенно существенно указанное замечание применительно к налогу на прибыль организаций, налоговая база которого обладает наибольшей способностью корреляции с налоговой базой по другим налогам. В связи с этим администрирование налога на прибыль организаций может быть упрощено в той степени, в которой база по другим налогам соответствует базе налогообложения прибыли. Это соответствие может уменьшать сложность определения базы налогообложения, которая измеряется как налогооблагаемая прибыль ${ }^{3}$.

\footnotetext{
${ }^{2}$ Твердохлебов В.Н. Финансовые очерки вып. I Петроград: 1916 г. С. 147.

${ }^{3}$ Алексеев М., Синельников С. Проблемы налоговой системы России: теория, опыт, реформа. Том 1. Институт экономики переходного периода. Научные труды № 19P. Москва, 2000. URL:
} 


\section{Налоги и налогообложение - №6(108) 2013}

Принцип учета взаимосвязи и взаимообусловленности налоговых баз по налогам, входящим в состав налоговой системы страны, должен выступать в качестве одного из основополагающих при формировании налоговой политики государства, от полноты и качества реализации которого зависит, в том числе, эффективность функционирования системы налогового администрирования.

Как подчеркивает Типалина M.B., в российском налоговом законодательстве, на сегодняшний день, должного внимания взаимосвязи и взаимовлиянию налогов не уделено, прослеживается лишь формальная связь налогов, например, участие одного налога в формировании налоговой базы другого, использование норм одной главы НК РФ при исчислении другого налога ${ }^{4}$. Таким образом, вопросы взаимосвязи норм различных глав НК РФ, являющиеся частным случаем взаимосвязи налоговых баз, нуждаются в общетеоретическом обосновании.

Отметим, что попытки исследования корреляции налогов, входящих в состав налоговой системы РФ, ранее хотя и предпринимались, но в достаточно ограниченном количестве публикаций.

Ильин A.B. ${ }^{5}$ предлагает все налоги в зависимости от экономического механизма функционирования разделить на взаимосвязанные и не взаимосвязанные.

http://www.budgetrf.ru/Publications/Analysis/iet/ an_iet_250902/an_iet_250902080.htm (дата обращения: 30.01.2010).

${ }^{4}$ Типалина М.B. Реализация налоговой политики государства в области налогообложения прибыли. Дис. ... канд. экон. наук. Москва, 2007. С. 127.

${ }^{5}$ Ильин А.В. Взаимосвязанное налогообложение: вопросы теории и практики. Финансы, 2003, № 12.
В основе экономического механизма взимания взаимосвязанных налогов у налогоплательщиков-контрагентов лежит определенная связь. Суть демаркации взаимосвязанных и не взаимосвязанных налогов автор видит в зависимости изменения налоговых обязательств в результате сделки у одного налогоплательщика от изменения налоговых обязательств другого налогоплательщика-контрагента по сделке. Так, например, взаимосвязанными налогами выступают НДС и налог на прибыль организаций, а к числу не взаимосвязанных следует отнести налог на имущество организаций, транспортный, земельный и другие налоги.

Типалина M.В. останавливается на анализе норм НК РФ о налоге на прибыль организаций на предмет их взаимосвязи с положениями глав по другим налогам. Одновременно автор предлагает рассматривать взаимосвязанное налогообложение в нескольких сферах и выделяет следующие направления влияния налогов:

- взаимосвязь налоговых баз различных налогов у отдельно взятого налогоплательщика с целью выявления влияний изменений законодательства, либо учетной политики на налоговые обязательства организации;

- взаимосвязь налоговых обязательств налогоплательщиков-контрагентов по конкретной сделке;

- взаимосвязь налоговых баз по ряду налогов с точки зрения государства с целью анализа влияния результата изменения законодательства на поступления в бюджетную систему РФ;

- анализ взаимосвязи норм соответствующей главы НК РФ и норм исчисления 
налогооблагаемой базы по другим налогам ${ }^{6}$.

Представляется, что предпосылки, обусловливающие пересечение и взаимосвязь налоговых баз, вытекают из сущности воспроизводственного процесса, в ходе которого осуществляют взаимодействие различные хозяйствующие субъекты, население и органы государственной власти всех уровней, а также связей между основными экономическими показателями, отдельные виды которых выступают объектами налогообложения.

Обоснование взаимосвязи налоговых баз представляется возможным построить на основе выработанной теорией и практикой налогообложения в ходе своей длительной эволюции классификации налогов по способу их взимания, в соответствии с которой все налоги делятся на прямые и косвенные.

Объектом налогообложения прямых личных налогов выступают показатели, отражающие уровень платежеспособности налогоплательщиков, как правило - прибыль и (или) доход. При этом прибыль является показателем, который используется в основном при налогообложении организаций, доход - при налогообложении населения.

В связи с тем, что прибыль является одним из наиважнейших экономических показателей, ее налогообложение в той или иной форме осуществляется в любой стране мира. Следует обратить внимание, что прибыль представляет собой расчетный показатель, характеризующий

6 Типалина M.B. Реализация налоговой политики государства в области налогообложения прибыли. Дис. ... канд. экон. наук. Москва, 2007. С. 128. абсолютный результат предпринимательской деятельности хозяйствующих субъектов, для расчета которого используется ряд других экономических категорий. В самом абстрактном виде прибыль представляет собой разницу между доходами и расходами, что учитывается и в процессе налогообложения. Доходы экономических агентов складываются из выручки от реализации товаров (работ, услуг) и поступлений от многообразных прочих (внереализационных) операций. Расходы также характеризуются большим количеством видов и многогранностью, что зависит от специфики деятельности фирм: расходы на приобретение основных и оборотных фондов, заработную плату, рекламу, маркетинг и многие другие.

Доходы населения в основной массе формируются за счет выплат, осуществляемых фирмами в качестве оплаты фактора производства «труд», то есть заработной платы. С позиции организаций заработная плата, напротив, выступает издержками, которые учитываются при формировании прибыли и, соответственно, налоговой базы по налогу на прибыль организаций. Таким образом, налоговая база по прямым личным налогам, которыми облагаются доходы населения, полученные в виде заработной платы, может учитываться в составе расходов при формировании налоговой базы по прямым личным налогам, которыми облагается прибыль организаций.

Полежаев В.А., обосновывая в своих работах целесообразность налогообложения расходов, использует понятия одновекторных и разновекторных налогов в зависимости от влияния изменений нало- 


\section{Налоги и налогообложение - №6(108) 2013}

говой базы по одному налогу на изменения налоговой базы по другим налогам Используя критерий векторной направленности, для удобства дальнейшего анализа, можно признать налоговые базы налогов, которые однонаправлено изменяются в зависимости от роста или снижения однотипного экономического показателя, используемого при их формировании, одновекторными. Налоговые базы налогов, которые разнонаправлено изменяются в зависимости от роста или снижения однотипного показателя, используемого при их формировании, напротив, правомерно рассматривать в качестве разновекторных. Исходя из этого налоговые базы по налогу на прибыль организаций и налогу на доходы физических лиц в части выплат по трудовым договорам будут рассматриваться в качестве разновекторных, поскольку увеличение показателя фонда оплаты труда приведет к увеличению налоговой базы по налогу на доходы физических лиц и к уменьшению налогооблагаемой прибыли.

Важным выводом, вытекающим из вышеизложенного, является способность к корреляции налоговых баз по налогам, уплачиваемым разными категориями налогоплательщиков - организациями и физическими лицами.

Заработная плата и иные выплаты работникам, связанные с выполнением ими функций на основании трудового договора, выступают не только объектом налогообложения по прямым личным налогам, которыми облагаются доходы населения, но и объектом обложения специализированных налогов (взносов), поступления

\footnotetext{
${ }^{7}$ Полежаев В.А. О разновекторной модели налогообложения. Финансы, 2004, № 9.
}

от которых формируют доходы целевых социальных государственных фондов, за счет которых осуществляется финансирование расходов на выплату населению пенсий, социальных пособий, расходов на медицинское обслуживание. В связи с тем, что при росте выплат в пользу физических лиц происходит увеличение баз для исчисления налога на доходы и специализированных социальных налогов, их взаимосвязь следует признать одновекторной . Одновременно с этим, учитывая взаимосвязь заработной платы и прибыли как экономических категорий, можно прийти к выводу о разновекторной взаимосвязи налоговой базы по специализированным социальным налогам с налоговой базой по прямым личным налогам, которыми облагается прибыль, относительно показателя выплат в пользу физических лиц.

Объектами налогообложения прямых реальных налогов, как правило, выступают различные виды имущества (возможно и нематериальных активов) хозяйствующих субъектов и населения, наличие которых само по себе не позволяет делать обоснованных выводов о фактической платежеспособности налогоплательщиков. В качестве самостоятельных объектов налогообложения могут выступать транспортные средства, основные средства, непроизводственное оборудование и прочие объекты. С позиции организаций стоимость приобретенного имущества выступает издержками, снижающими общий объем доходов и, соответственно, прибыли. В этом случае возможно пересечение отдельных элементов формирования налоговой базы по прямым личным налогам, которыми облагается прибыль, и прямым реальным налогам. Однако для реализации такой 
возможности, как минимум, необходимо выполнение ряда условий. Во-первых, масштаб прямых реальных налогов должен иметь стоимостное выражение, поскольку прибыль выступает стоимостной категорией. Во-вторых, при исчислении налоговых баз должны использоваться единые виды стоимости (первоначальная, остаточная, восстановительная, рыночная и др.), единые правила их определения и источники информации о них.

Указанные замечания относительно тождества масштаба налогов, использования единых видов стоимости и правил их определения на основе единых информационных массивов являются необходимыми условиями для пересечения налоговых баз по разным налогам. Так, например, если налоговая база по прямому реальному налогу будет формироваться исходя из остаточной стоимости основных средств, сформированной по данным налогового учета, то сумма амортизационных отчислений, учитываемая при исчислении налоговой базы по налогу на прибыль организаций, будет равняться сумме амортизационных отчислений, принимаемой в расчет при исчислении налоговой базы по прямому реальному налогу, что в данном случае свидетельствует об их одновекторной взаимосвязи.

Косвенными налогами, к которым относят акцизы, таможенные пошлины и фискальные монополии, обычно облагаются операции по реализации товаров (работ, услуг) или отдельные действия налогоплательщиков. В результате реализации товара (работы, услуги) фирма получает от покупателя определенную сумму денежных средств, признаваемую выручкой от реализации и формирующей ее доходы, которая может облагаться универсальным и (или) индивидуальным акцизом. Таким образом, можно констатировать, что налоговая база по индивидуальным акцизам в общем случае должна одновекторно коррелировать с налоговой базой по универсальным акцизам, являясь ее составной частью. Доход в виде выручки от реализации, в свою очередь, является показателем, непосредственно влияющим на величину прибыли организации. Следовательно, выручка от реализации, облагаемая акцизами, в общем случае участвует при исчислении прибыли, что приводит к тому, что налоговая база по акцизам может учитываться при формировании налоговой базы по прямым личным налогам, которыми облагается прибыль налогоплательщика, а именно - при определении показателя выручки от реализации, что свидетельствует об их одновекторной взаимосвязи.

Исходя из вышеизложенного можно констатировать, что налоговая база по прямым личным налогам, которыми облагается прибыль хозяйствующих субъектов, способна учитывать в себе:

- налоговую базу по косвенным налогам - при формировании показателя выручки от реализации;

- налоговую базу по прямым личным налогам, которыми облагается заработная плата работников и специализированным социальным налогам (взносам) - при формировании показателя расходов на оплату труда;

- $\quad$ налоговую базу или ее отдельные элементы по прямым реальным налогам - при формировании отдельных расходных статей. 


\section{Налоги и налогообложение - №6(108) 2013}

При этом налоговая база по косвенным налогам в таком случае будет пересекаться с показателями, используемыми при исчислении доходной части налоговой базы по налогу на прибыль организаций, а налоговые базы по иным налогам - с показателями, используемыми при исчислении расходной части налоговой базы по налогу на прибыль организаций.

В то же время представляется, что полная унификация механизмов исчисления потенциально способных к корреляции налоговых баз существенно затрудняется необходимостью реализации регулирующей функции различных налогов, которые хотя и имеют сходные элементы в части формирования налоговой базы, но все же по-разному воздействуют на социальноэкономические процессы. Приведенная позиция согласуется с мнением Каллистовой Ю.И.: обладая общими свойствами, присущими налогам как экономической категории, отдельные налоговые платежи отличаются по своему экономическому содержанию. Последнее проявляется через элементы налога ${ }^{8}$.

Потенциально возможные расхождения в порядке формирования налоговых баз, способных к корреляции, чаще всего обусловливаются встроенным в них механизмом налогового стимулирования, освобождающим отдельные виды доходов, имущества и иных элементов, принимающих участие в формировании налоговой базы, от налогообложения. Разнородность предоставляемых налогоплательщикам преференций по разным налогам с одно-

${ }^{8}$ Каллистова Ю.И. Прибыль как объект налогообложения и источник платежей организаций в бюджет. Дис. ... канд. экон. наук. Москва, 2002. С. 9. типными элементами формирования налоговой базы удаляет от идеи унификации налоговых баз и делает налоговую систему сложной для администрирования.

Представляется, что при совпадении направлений регулирующего воздействия налогов с взаимосвязанными налоговыми базами на налогоплательщиков и социально-экономические процессы льготирование на стадии формирования налоговых баз должно осуществляться с учетом их системной связи и векторной направленности.

Налог на прибыль организаций и НДС, увеличение налоговых баз по которым одновекторно зависит от показателя выручки от реализации, непосредственным образом влияют на финансовое состояние организаций-налогоплательщиков и используются для регулирования инвестиционной активности, развития отдельных отраслей и видов деятельности и других аналогичных процессов, во многом зависящих от объемов финансовых средств, остающихся в распоряжении налогоплательщиков. В связи с этим при определении показателя выручки от реализации, учитываемого при исчислении налоговых баз по вышеуказанным налогам, целесообразно предоставление однородных льгот, являющихся объективным отражением основных тенденций экономической и налоговой политики государства. Разнородность налоговых льгот и правил формирования показателя выручки от реализации в данном случае, напротив, представляется непоследовательным обстоятельством. Аналогичная ситуация возникает при рассмотрении правил формирования налоговых баз по налогу на доходы населения и специализированным социальным налогам (взносам) 
- их налоговые базы наиболее удобны для унификации.

Налоговые базы налога на прибыль организаций и НДС, налога на доходы населения и специализированных социальных налогов являются одновекторными в отношении показателя выручки от реализации и фонда оплаты труда соответственно. Однако данный факт не позволяет говорить о том, что только налоги с одновекторными налоговыми базами способны к полной или частичной унификации правил формирования базы налогообложения. Так, например, существовавший в российской налоговой системе налог на рекламу, налоговая база которого формировалась, в том числе, исходя из величины рекламных расходов налогоплательщиков, которые, в свою очередь, учитывались в составе расходов при исчислении налогооблагаемой прибыли. Указанные налоговые базы выступают разновекторно взаимосвязанными в отношении показателя расходов на рекламу, однако способны к полной унификации в отношении правил его определения.

Вместе с тем представляется, что использование однородных налоговых льгот по налогам с разновекторными налоговыми базами не корректно по причине их различного влияния на социальноэкономические процессы. Например, существенные затруднения по сближению правил формирования налоговых баз возникают в отношении прямых реальных налогов и налогов, основой для исчисления которых являются выплаты физическим лицам за выполнение ими трудовых обязанностей - прямого личного налога на доходы населения и специализированных социальных налогов. Необходимость ос- вобождения от налогообложения наиболее значимых выплат в пользу физических лиц, призванного способствовать обеспечению минимально необходимого уровня материального обеспечения населения и поддержке социальной стабильности в обществе, не согласуется с одновременной необходимостью признания таких выплат работникам при исчислении налогооблагаемой прибыли в полном объеме. Вывод изпод налогообложения отдельных выплат в пользу физических лиц в то же время подразумевает стимулирование работодателей-организаций к их осуществлению, что достигается путем разрешения на их учете при исчислении налоговой базы по прямому реальному налогу на прибыль. Таким образом, налоговые базы по прямому личному налогу на доходы населения и специализированным социальным налогам с учетом вышеизложенного вряд ли смогут без корректировок использоваться при исчислении налоговой базы по налогу на прибыль организаций в составе расходов на оплату труда.

Однако следует понимать, что регулирование социально-экономических процессов посредством налогов отнюдь не заключается в маневрировании порядка исчисления налоговых баз - преференции могут учитываться при установлении иных элементов налогообложения. Так, например, отмена освобождения от налогообложения доходов, учитываемых при формировании налоговых баз по налогам, исчисляемым с выплат в пользу физических лиц, приводящая к сближению правил формирования налоговых баз по данным налогам с правилами учета расходов на оплату труда при исчислении налогооблагаемой прибыли, может ком- 
DOI: $10.7256 / 1812-8688.2013 .6 .2605$

При цитировании этой статьи сноска на dоі обязательна

\section{Налоги и налогообложение - №6(108) 2013}

пенсироваться соразмерным снижением налоговых ставок.

Применительно к российской действительности следует отметить, что в Основных направлениях налоговой политики, одобренных на заседании Правительства РФ 02.03.2007 № 8, говорится о том, что в результате осуществления налоговой реформы, в том числе, была решена проблема упрощения налоговой системы за счет максимальной унификации налоговых баз и правил их исчисления по отдельным налогам. Однако и в настоящее время правила формирования показателя выручки от реализации для целей исчисления налогооблагаемой прибыли и налоговой базы по НДС, порядка расчета сумм амортизации для целей исчисления расходов по налогу на прибыль и остаточной стоимости основных средств при определении налоговой базы по налогу на имущество организаций существенно отличаются, что не позволяет прийти к выводу о достижении максимально возможной унификации взаимосвязанных налоговых баз в российской налоговой системе. Следует отметить, что существующие отличия в порядке определения взаимосвязанных налоговых баз по большей части носят методический характер и не обусловлены целями налогового регулирования, что является неоправданным.

Корреляция налоговых баз и их отдельных элементов подводит к рассмотрению вопросов квалификации обязательных платежей в бюджетную систему страны и определения субъекта контроля за их уплатой. Представляется, что рациональная организация налоговой системы должна предполагать включение всех обязательных платежей, обладающих законодатель- но установленными признаками налогов и сборов, в соответствующую систему, подведомственную единым контролирующим органам. Указанный порядок организации налоговой системы позволит производить изменения налогового законодательства с учетом системной взаимосвязи налоговых баз, комплексно анализировать влияние изменений в исчислении налоговых баз по одним налогам на базы для исчисления других налогов, создавать единые методики контроля за правильностью их исчисления, препятствовать рассредоточению единых полномочий и функций налоговых органов, и, как следствие, дальнейшей бюрократизации государственного аппарата, что окажет положительное влияние на всю систему налогового администрирования.

Необходимость трансформации системы пенсионного обеспечения повлекла за собой очередную реформу российской налоговой системы, в результате которой был осуществлен переход от уплаты единого социального налога к уплате отдельных страховых взносов в государственные внебюджетные фонды. Вместе с тем произошла передача контрольных полномочий налоговых органов в отношении указанных платежей к Пенсионному фонду РФ и его территориальным органам, что с точки зрения комплексного управления налоговой системой значительно сократило эффективность. Во-первых, единый социальный налог достаточно прочно укоренился в российской системе налогов и сборов, став ее неотьемлемой частью, порядок формирования налоговой базы которого был поставлен в зависимость от порядка формирования налоговых баз по другим налогам, в частности, по налогу на прибыль организаций. Во-вторых, за годы 
функционирования единого социального налога налоговые органы накопили положительный опыт проведения контрольных мероприятий за правильностью его исчисления и своевременностью уплаты, в том числе, с учетом его взаимосвязи с другими налогами. Представляется, что в результате проведенной реформы у новых контролирующих органов могут возникнуть сложности с обеспечением действенного контроля за уплатой вновь введенных страховых взносов по причине не только отсутствия соответствующего опыта, но и искусственного разрыва довольно схожих по механизму формирования налоговой базы налога на доходы физических лиц и единого социального налога, которые администрировались взаимосвязанно налоговыми органами.

Резюмируя вышеизложенное, следует признать, что работа по унификации налоговых баз и правил их определения в российской налоговой системе все-таки не завершена и требует своего продолжения.

\section{Библиография:}

1. Алексеев М., Синельников С. Проблемы налоговой системы России: теория, опыт, реформа. Том 1. Институт экономики переходного периода. Научные труды № 19P. Москва, 2000. URL: http:// www.budgetrf.ru/Publications/Analysis/ iet/an_iet_250902/an_iet_250902080.htm (дата обращения: 30.01.2010);

2. Гончаренко Л.И. Методология налогообложения и налогового администрирования коммерческих банков России. Афтореф. дис. ... док. экон. наук. Москва, 2009. 43 с.;
3. Ильин А.В. Взаимосвязанное налогообложение: вопросы теории и практики. Финансы, 2003, № 12;

4. Каллистова Ю.И. Прибыль как объект налогообложения и источник платежей организаций в бюджет. Дис. ... канд. экон. наук. Москва, 2002. 217 с.;

5. Основные направления налоговой политики, одобрены на заседании Правительства РФ (протокол от 02.03.2007 № 8);

6. Полежаев В.А. О разновекторной модели налогообложения. Финансы, 2004, № 9;

7. Твердохлебов В.Н. Финансовые очерки вып. I - Петроград: 1916 г. С. 147;

8. Типалина М.В. Реализация налоговой политики государства в области налогообложения прибыли. Дис. ... канд. экон. наук. Москва, 2007. 181 с.

\section{References (transliteration):}

1. Alekseev M., Sinel'nikov S. Problemy nalogovoy sistemy Rossii: teoriya, opyt, reforma. Tom 1. Institut ekonomiki perehodnogo perioda. Nauchnye trudy № 19R. Moskva, 2000. URL: http://www.budgetrf.ru/Publications/ Analysis/iet/an_iet_250902/an_ iet_250902080.htm (data obrascheniya: 30.01.2010);

2. Goncharenko L.I. Metodologiya nalogooblozheniya i nalogovogo administrirovaniya kommercheskih bankov Rossii. Aftoref. dis. ... dok. ekon. nauk. Moskva, 2009. 43 s.;

3. Il'in A.V. Vzaimosvyazannoe nalogooblozhenie: voprosy teorii i praktiki. Finansy, 2003, № 12; 
DOI: $10.7256 / 1812-8688.2013 .6 .2605$

При цитировании этой статьи сноска на dоі обязательна

Налоги и налогообложение - №6(108)• 2013

4. Kallistova Yu.I. Pribyl' kak ob'ekt nalogooblozheniya i istochnik platezhey

6. Tverdohlebov V.N. Finansovye ocherki vyp. I - Petrograd: 1916 g. S. 147; organizaciy v byudzhet. Dis. ... kand. ekon. nauk. Moskva, 2002. 217 s.;

5. Polezhaev V.A. O raznovektornoy modeli nalogooblozheniya. Finansy, 2004, № 9;

7. Tipalina M.V. Realizaciya nalogovoy politiki gosudarstva v oblasti nalogooblozheniya pribyli. Dis. ... kand. ekon. nauk. Moskva, 2007. 181 s. 